\title{
Perfil das ações judiciais em assistência à saúde com bloqueio de verbas públicas no Estado de Santa Catarina
}

Profile of lawsuits in health care with blockade of public funds in the state of Santa Catarina, Brazil

Perfil de los juicios en salud con bloqueo de fondos públicos en el estado de Santa Catarina, Brasil

Sabrina Hoffmann Vilvert ${ }^{1}$

Fabíola Bagatini Buendgens ${ }^{2}$

Orozimbo Henriques Campos $\mathrm{Neto}^{3}$

Haliton Alves de Oliveira Júnior ${ }^{4}$

\section{Resumo}

Objetivo: analisar o perfil situacional dos bloqueios de valores decorrentes do descumprimento de decisões judiciais em assistência à saúde, no Estado de Santa Catarina. Métodos: foram considerados os processos com determinação de bloqueio nas contas do Estado de Santa Catarina, nos meses de dezembro de 2015 e dezembro de 2016, em que os autores requereram medicamentos, insumos e nutrição. Resultados: a maioria das ações são ajuizadas individualmente e por escritórios de advocacia particulares. Medicamentos configuraram como o objeto mais solicitado, prescritos em sua maioria pelo nome comercial e não padronizados em listas oficiais em mais de $70 \%$ dos casos. Em 2015, o gasto mensal foi de $R \$ 135.549,39$, e, caso o Estado tivesse realizado a aquisição, o gasto mensal seria de $R \$ 82.016,29$. Em dezembro de 2016, o gasto com bloqueio foi de $R \$ 833.634,88$, enquanto por meio de compra administrativa seria de $\mathrm{R} \$ 447.357,68$. Observou-se um crescimento de $858,82 \%$ dos gastos com bloqueios, do ano de 2015 para 2016. Conclusões: os resultados obtidos podem contribuir para o melhor planejamento do cumprimento das decisões judiciais em saúde, evitando que não onerem ainda mais os cofres públicos e prejudiquem o orçamento da saúde pública.

Palavras-chave: Direito à saúde. Judicialização da saúde. Acesso a medicamentos. Gastos em saúde. Assistência à saúde.

\footnotetext{
1 Farmacêutica no Núcleo de Apoio Técnico da Secretaria do Estado da Saúde de Santa Catarina; MBA em Economia em Avaliação de Tecnologias em Saúde. E-mail: vilvertsh@gmail.com

2 Doutora em Farmácia; farmacêutica no Núcleo de Apoio Técnico da Secretaria do Estado da Saúde de Santa Catarina pesquisadora no Grupo de Pesquisa Políticas e Serviços Farmacêuticos da Universidade Federal de Santa Catarina. Email: fbagatinib@gmail.com

3 Doutor em Saúde Pública; mestre em Saúde Pública; diretor na Atenção Primária e Vigilância em Saúde da Secretaria Municipal de Saúde de Pedro Leopoldo, Pedro Leopoldo, Minas Gerais, Brasil; professor do curso de graduação em Farmácia na Faculdade Ciências da Vida em Sete Lagoas, Minas Gerais, Brasil; pesquisador colaborador do Grupo de Pesquisa em Economia da Saúde (GPES/UFMG), Belo Horizonte, Minas Gerais, Brasil. E-mail: zimboneto@yahoo.com.br 4 Mestrado e doutorado em Medicamentos e Assistência Farmacêutica/Farmacoepidemiologia; pesquisador na Unidade de Avaliação de Tecnologias em Saúde (UATS) do Hospital Alemão Oswaldo Cruz; coordenador científico do Projeto Protocolos Clínicos e Diretrizes Terapêuticas, em parceria com o Ministério da Saúde via PROADI-SUS, São Paulo, Brasil. E-mail: haoliveira@haoc.com.br
} 


\begin{abstract}
Objective: to analyze the situational profile of value blocks resulting from non-compliance with health care court decisions in the State of Santa Catarina. Methods: re considered the processes with determination of blockage in the accounts of the State of Santa Catarina, in December 2015 and December 2016, in which the authors requested drugs, inputs and nutrition. Results: most actions are filed individually and by private law firms. Medicines were the most requested object, mostly prescribed by trade name and not standardized on official lists in more than $70 \%$ of cases. In 2015 , the monthly expense was $R \$ 135,549.39$, and if the State had made the acquisition, the monthly expense would be $R \$ 82,016.29$. In December 2016 , the cost of blocking was $R \$ 833,634.88$, while through administrative purchase would be $\mathrm{R} \$ 447,357.68$. There was a growth of $858.82 \%$ in spending on blockages, from 2015 to 2016. Conclusions: the results obtained can contribute to better planning compliance with health court decisions, avoiding that they do not burden the public coffers even more and undermine the public health budget.

Keywords: Right to health. Health's judicialization. Access to essential medicines and health technologies. Health expenditures. Delivery of health care.
\end{abstract}

\title{
Resumen
}

Objetivo: analizar el perfil situacional de los bloques de valor resultantes del incumplimiento de las decisiones de los tribunales de atención médica en el Estado de Santa Catarina. Métodos: Consideramos los procesos con determinación de bloqueo en las cuentas del Estado de Santa Catarina, en diciembre de 2015 y diciembre de 2016, en los que los autores solicitaron medicamentos, insumos y nutrición. Resultados: la mayoría de las demandas se presentan individualmente y por firmas de abogados privadas. Las drogas fueron el objeto más solicitado, en su mayoría recetados por nombre comercial y no estandarizados en las listas oficiales en más del $70 \%$ de los casos. En 2015 , el gasto mensual fue de $\mathrm{R} \$$ $135.549,39$, y si el Estado hubiera realizado la adquisición, el gasto mensual sería de $R$ \$ $82.016,29$. En diciembre de 2016 , el costo del bloqueo fue de $R \$ 833,634.88$, mientras que a través de la compra administrativa sería de $R \$ 447,357.68$. Hubo un crecimiento del $858.82 \%$ en el gasto en bloqueos, de 2015 a 2016. Conclusiones: los resultados obtenidos pueden contribuir a una mejor planificación del cumplimiento de las decisiones judiciales en salud, evitando que no carguen aún más las arcas públicas y socavaren el presupuesto de salud pública.

Palabras-llave: Derecho a la salud. Judicialización de la Salud. Acceso a medicamentos esenciales y tecnologías sanitarias. Gastos en Salud. Prestación de atención de salud.

\section{Introdução}

O uso da expressão judicialização da saúde vem se tornando corriqueiro, pois cada vez mais os indivíduos recorrem à justiça para obtenção de aportes necessários aos seus tratamentos, apontando para problemas no acesso a bens e serviços na área da saúde (1). A via judicial, como principal meio para garantir o acesso, configura o sistema de justiça como alternativa de entrada no sistema público de saúde e pode descaracterizar os princípios e diretrizes do Sistema Único de Saúde (SUS) referentes ao acesso ao sistema (2). 
O crescimento desordenado das ações judiciais em assistência à saúde, à medida que impõe gastos inesperados aos orçamentos municipais, estaduais e federal, causa grande impacto à gestão do SUS (3). No ano de 2016, o Estado de Santa Catarina gastou aproximadamente $\mathrm{R} \$ 116$ milhões com o cumprimento de decisões judiciais em assistência em saúde, além do bloqueio de $\mathrm{R} \$ 39,8$ milhões em suas contas. Nos anos de 2017 e 2018, foram gastos com o cumprimento de ações judiciais, respectivamente, $R \$ 128.398 .737,48$ e $\mathrm{R} \$ 184.669 .028,34(4)$.

O descumprimento de decisões judiciais em assistência à saúde tem aumentado as solicitações de bloqueio de verbas públicas, com o intuito de garantir o fornecimento ininterrupto do tratamento pleiteado ao autor da ação judicial (5). A Proposta de Súmula Vinculante (PSV) $n^{\circ} 4$, apresentada pela Defensoria Pública da União (DPU), tem o objetivo de garantir que fique expressa a

possibilidade de bloqueio de valores públicos para o fornecimento de medicamentos e tratamento médico ao carente, comprovada a necessidade do fármaco ou da intervenção médica, restando afastada, por outro lado, a alegação de que tal bloqueio fere o art. 100, caput e $\S 2^{\circ}$, da Constituição de 1988. (7)

O Parecer da Procuradoria Geral da República (PGR) foi pela aprovação da proposta, com os seguintes dizeres: “(...) legitima a determinação de bloqueio de verbas públicas que assegurem o cumprimento da decisão condenatória, sem que se possa alegar, quanto à ordem de bloqueio, ofensa ao art. 100, § $2^{\circ}$, da Constituição Federal” (6).

Em 16 de abril de 2015, o então Presidente do Supremo Tribunal Federal (STF), Ministro Ricardo Lewandowski, em relação à PSV no 4, posicionou-se apenas quanto à responsabilidade solidária da União, Estados, Municípios e o Distrito Federal: "É solidária a responsabilidade dos entes federativos para o fornecimento de medicamento e tratamento médico das pessoas carentes." (6) A Comissão de Jurisprudência determinou a interrupção do processo até o julgamento do mérito do Recurso Extraordinário (RE) ํㅜ 566.471, de relatoria do Ministro Marco Aurélio Melo do STF. O núcleo da discussão no referido RE é o fornecimento de medicamento de alto custo, não contemplado no respectivo programa de dispensação, por parte dos entes federados e a suposta violação dos artigos 5ำ 6ำ, 196, e 198, $\S^{10}$ e $\S 2^{\circ}$, da Constituição Federal, em razão de condenação judicial.

O sequestro de verbas públicas para fornecimento de medicamentos já foi 
fundamentado pelo STF, conforme a controvertida criação jurisprudencial (STJ. 1ํㅗ Seção. REsp 1.069.810-RS, Rel. Min. Napoleão Nunes Maia Filho, julgado em 23/10/2013 - recurso repetitivo) (8). Tal decisão tem possibilitado que os magistrados determinem o bloqueio de verbas nas contas dos entes federativos. Sendo assim, este estudo teve como objetivos estimar os gastos associados aos bloqueios de verbas públicas referentes ao descumprimento de decisões judiciais em assistência à saúde no Estado de Santa Catarina, nos meses de dezembro de 2015 e dezembro de 2016; traçar um perfil desses processos; e comparar os gastos com o bloqueio versus o gasto da compra pelo Estado.

\section{Métodos}

Realizou-se uma análise do perfil situacional do bloqueio de contas públicas, a partir de um estudo observacional e descritivo. Foram selecionados os processos judicializados contra o Estado de Santa Catarina, em curso na Justiça Estadual e na Justiça Federal, que tiveram determinação de bloqueio de contas públicas e que foram encaminhados à Secretaria de Estado da Saúde de Santa Catarina (SES/SC), nos meses de dezembro de 2015 e dezembro de 2016. Consultou-se a ferramenta de gerenciamento de dados do setor responsável da SES/SC, a partir da qual foi possível identificar os processos alvos da pesquisa. Foram excluídos da análise os processos relacionados a procedimentos e equipamentos em saúde, e aqueles cuja determinação de bloqueio não tivesse ocorrido nos meses em destaque. Considerou-se como perdas os processos que não apresentaram todas as informações referentes às variáveis analisadas, as quais foram categorizadas em três grupos, conforme demonstrado no Quadro 1.

Quadro 1. Variáveis analisadas no estudo

\begin{tabular}{l|l}
\hline \multicolumn{1}{c}{ Variáveis } & \multicolumn{1}{c}{ Categorias } \\
\hline & - Concentração \\
& - Contracautela \\
& - Denominação Comum Brasileira (DCB) \\
& - Indicação judicializada aprovada em bula \\
Variáveis da tecnologia & - Juiz permite troca por genérico \\
& - Lista oficial (Remume, Rename, CIB) \\
& - Nome comercial \\
& - Origem receituário (SUS ou não-SUS) \\
\hline
\end{tabular}




\begin{tabular}{|c|c|}
\hline & $\begin{array}{l}\text { - Periodicidade } \\
\text { - Posologia } \\
\text { - Prescrição (por DCB, por nome } \\
\text { comercial) } \\
\text { - Registro na Anvisa } \\
\text { - Tipo de tecnologia (medicamento, } \\
\text { insumo, nutrição) } \\
\text { - Valor da tecnologia (caso fosse adquirida } \\
\text { pela SES/SC) }\end{array}$ \\
\hline Variáveis do autor & $\begin{array}{l}\text { - CID } 10 \\
\text { - Idade } \\
\text { - Município de residência }\end{array}$ \\
\hline Variáveis do processo & $\begin{array}{l}\text { - Comarca/subseção Judiciária } \\
\text { - Divisão do valor bloqueado entre os réus } \\
\text { - Representação processual } \\
\text { - Réu(s) } \\
\text { - Tempo de bloqueio pelo orçamento } \\
\text { - Tempo do bloqueio pela decisão } \\
\text { - Tipo da ação (ação civil pública, ordinária) } \\
\text { - Tipo do bloqueio (sequestro, } \\
\text { ressarcimento) } \\
\text { - Valor bloqueado pela decisão } \\
\text { - Valor bloqueado pelo orçamento }\end{array}$ \\
\hline
\end{tabular}

Fonte: elaboração própria.

Legenda: Anvisa (Agência Nacional de Vigilância Sanitária); CIB (Comissão Intergestores Bipartite); CID10 (Classificação Internacional de Doença); DPE (Defensoria Pública do Estado); DPU (Defensoria Pública da União); MPE (Ministério Público Estadual); MPF (Ministério Público Federal); Remume (Relação Municipal de Medicamentos); Rename (Relação Nacional de Medicamentos Essenciais); SES/SC (Secretaria do Estado de Saúde de Santa Catarina); SUS (Sistema Único de Saúde).

Os processos elegíveis em curso na Justiça Estadual (Comarcas) foram consultados no sítio eletrônico do Tribunal de Justiça de Santa Catarina (TJSC); os processos em curso na Justiça Federal (Subseções Judiciárias) foram consultados no sítio eletrônico da mesma.

As tecnologias analisadas foram classificadas como medicamentos, insumos e nutrição, sendo que, para os medicamentos, os registros e indicações registrados em bula foram consultados no sítio eletrônico da Agência Nacional de Vigilância Sanitária (Anvisa). A classificação estatística internacional de doenças e problemas relacionados à saúde (CID10) foi consultada no sítio eletrônico do Departamento de Informática do SUS (DataSUS) (9).

Para a atribuição do valor bloqueado, considerou-se o valor presente na decisão do 
bloqueio. O valor da tecnologia, caso fosse adquirida pelo Estado, foi estimado a partir do produto entre o valor unitário médio e a quantidade mensal utilizada. O valor unitário médio foi disponibilizado pela Gerência de Planejamento da Demanda de Bens e Serviços (GPLAD) da SES/SC, a partir das licitações ou compras diretas, realizadas nos anos de 2015 e 2016. Considerou-se as especificidades de cada tecnologia, tais como concentração e posologia para medicamentos, para a atribuição dos valores unitários. O gasto judicial e o possível gasto administrativo foram calculados a partir do mesmo horizonte temporal, considerando a mesma quantidade da tecnologia analisada.

Para cada um dos períodos analisados, o gasto total com bloqueio de valores foi estimado a partir do somatório de todos valores bloqueados após a decisão. Já para o valor gasto, caso a tecnologia tivesse sido adquirida pelo Estado, foi efetuado o somatório do valor mensal de todas as tecnologias, em ambos os períodos. Para uma investigação mais precisa, foram realizados três tipos de análise: 1) por processo; 2) por autor e; 3) por tecnologia, considerando que, em uma ação judicial, poderia constar mais de uma tecnologia e que um autor poderia ter mais de um processo. Os dados foram analisados no editor de planilhas Microsoft Office Exce/ß, versão 2016, e apresentados na forma de frequência absoluta e relativa.

O trabalho foi aprovado pelo Comitê de Ética em Pesquisa do Hospital Alemão Oswaldo Cruz, sob CAAE nำ68633917.2.0000.0070.

Importante destacar que devido a processos logísticos, administrativos e à complexidade na análise dos dados, foram analisados apenas dois meses em dois diferentes anos. Sendo assim, faz-se necessário ressaltar que o período analisado, apesar de indicar padrões relativos ao aumento do valor destinado ao bloqueio de verbas públicas, pode não ter sido suficiente para expressar com clareza o real panorama das decisões judiciais em ambos os anos. Dessa forma, devido ao viés temporal, a comparação dos achados entre os dois meses aqui analisados, assim como a situação atual da judicialização da saúde no Estado, podem estar sub ou superestimados. Adicionalmente, a comparação com mesmo mês, em ano subsequente, pode mascarar a sazonalidade do fenômeno ou as peculiaridades circunstanciais próprias da dinâmica no Judiciário. No entanto, os dados apresentados permitem o desenvolvimento de uma ideia, ainda que alusiva, da dimensão da problemática que é o bloqueio de valores, além de ser um dos poucos estudos que se 
propôs a avaliar o impacto desse fenômeno tão importante, em cenário real.

Devido à escassez de estudos referentes ao bloqueio de contas públicas para o cumprimento de decisões em assistência à saúde, houve dificuldade na discussão dos resultados encontrados. Em virtude disso, grande parte da discussão dos resultados foi baseada na comparação com achados provenientes de estudos sobre o perfil geral das ações judiciais.

\section{Resultados e discussão}

Perfil dos processos com bloqueio de verbas públicas

A partir da análise realizada, foram identificados 33 processos com bloqueio nas contas públicas do Estado de Santa Catarina em dezembro de 2015 e 184 em dezembro de 2016 (Tabela 1). Verificou-se um aumento de 557,58\% no número de solicitações de bloqueio, o que pode estar associado ao aumento das ações judiciais; ao maior conhecimento dos representantes jurídicos (advogados, defensores e promotores) desse tipo de solicitação nos autos; e à crise financeira que tem afetado os Estados, aumentando o descumprimento das decisões judiciais em saúde.

Tabela 1. Variáveis relacionadas aos processos com bloqueio de verbas públicas, nos meses de dezembro de 2015 e dezembro de 2016

\begin{tabular}{l|ll}
\hline \multirow{2}{*}{ Variável } & \multicolumn{2}{c}{ Mês/Ano } \\
\cline { 2 - 3 } & $\begin{array}{c}\text { Dezembro 2015 } \\
\%(\mathrm{n}=33)\end{array}$ & $\begin{array}{c}\text { Dezembro 2016 } \\
\%(\mathrm{n}=184)\end{array}$ \\
\hline Tipo da ação & $21,21 \%(7)$ & $9,78 \%(18)$ \\
Ação Civil Pública & $78,79 \%(26)$ & $90,22 \%(166)$ \\
Ação Ordinária & & \\
\hline Réu (s) & $63,64 \%(21)$ & $31,52 \%(58)$ \\
Estado & $21,21 \%(7)$ & $13,04 \%(24)$ \\
Estado e Município & $3,03 \%(1)$ & $3,26 \%(6)$ \\
Estado e União & $12,12 \%(4)$ & $52,17 \%(96)$ \\
Estado, Município e União & & \\
\hline Representação Processual & $42,42 \%(14)$ & $47,83 \%(88)$ \\
Advogado particular & $3,03 \%(1)$ & $0,00 \%(0)$ \\
Autor & $27,27 \%(9)$ & $6,52 \%(12)$ \\
Defensoria Pública Estadual &
\end{tabular}




\begin{tabular}{l|ll}
\hline \multirow{2}{*}{ Variável } & \multicolumn{2}{c}{ Mês/Ano } \\
\cline { 2 - 3 } & $\begin{array}{c}\text { Dezembro 2015 } \\
\%(\mathrm{n}=33)\end{array}$ & $\begin{array}{c}\text { Dezembro 2016 } \\
\%(\mathrm{n}=184)\end{array}$ \\
\hline Defensoria Pública Federal & $\begin{array}{c}3,03 \%(1) \\
5,98 \%(11)\end{array}$ & $28,80 \%(53)$ \\
Escritório Modelo & $0,00 \%(0)$ & $9,24 \%(17)$ \\
Ministério Público Estadual & $24,24 \%(8)$ & $1,63 \%(3)$ \\
Ministério Público Federal & $0,00 \%(0)$ & \\
\hline Tipo de bloqueio & & $84,78 \%(156)$ \\
Bloqueio & $72,73 \%(24)$ & $10,33 \%(19)$ \\
Ressarcimento & $18,18 \%(6)$ & $4,89 \%(9)$ \\
Bloqueio e Ressarcimento & $9,09 \%(3)$ & $94,57 \%(174)$ \\
\hline Divisão do valor bloqueado entre os réus & & $3,26 \%(6)$ \\
100\% Estado & $96,97 \%(32)$ & $1,63 \%(3)$ \\
$50 \%$ Estado e 50\% Município & $3,03 \%(1)$ & $0,54 \%(1)$ \\
$50 \%$ Estado e 50\% União & $0,00 \%(0)$ & \\
$33 \%$ Estado, 33\% Município e 33\% União & $0,00 \%(0)$ & \\
\hline
\end{tabular}

Fonte: elaboração própria.

Entre os processos analisados, as ações ordinárias, predominaram em ambos os períodos, corroborando o perfil geral das ações judiciais encontrado em estudos prévios (3) (10-12), cuja maioria é requerida individualmente, caracterizando a busca do indivíduo pelo seu direito previsto em constituição. Cabe salientar que não foram localizados mandados de segurança na análise sobre os tipos de decisões. De acordo com Schulze (13), algumas Cortes entendem que não é possível ajuizar como mandado de segurança, diante da impossibilidade de produção de provas durante o processo, como é o caso do TJSC e do Tribunal Regional Federal da 4⿳亠丷 Região.

Como o estudo foi conduzido na SES/SC, era previsto um grande volume de ações movidas tendo apenas o Estado como réu. Em dezembro de 2015, o Estado sozinho configurou como réu em 63,64\% dos processos analisados; em contrapartida, em 2016, a maioria dos processos apresentou os três entes federativos como réus. Essa alteração de cenário pode estar relacionada à estratégia de representantes jurídicos de que uma ação judicial contra os três entes pode aumentar a probabilidade de deferimento ou até mesmo ao desconhecimento das políticas públicas e competências de cada ente, somada ao fato do STF ainda manter a responsabilidade solidária. O STF, em 2015, diante de RE (14) interposto pela União, decidiu que o tratamento médico adequado aos necessitados se 
insere no rol dos deveres do Estado, sendo de responsabilidade solidária dos entes federados, podendo o polo passivo ser composto por qualquer um deles, isoladamente ou conjuntamente. A decisão final ainda não foi proferida pelo STF.

Existem Portarias do Ministério da Saúde que definem os medicamentos padronizados nos componentes da assistência farmacêutica e a responsabilidade de financiamento de cada um dos entes, no entanto são desconsideradas. A tese da responsabilidade solidária dos entes federativos (15) no cumprimento das prestações de saúde é um tipo de interpretação constitucional, com base no artigo 23 , que trata das competências comuns dos entes federativos relativas à assistência pública em saúde. Essa interpretação não condiz com as diretrizes de organização do SUS, em termos de integração dos serviços de saúde entre entes federativos assimétricos, social, econômica, demograficamente e na observância de níveis de complexidade tecnológica dos serviços. Essa divisão de responsabilidade é realizada por negociação nas Comissões Intergestores Regionais (CIR), Bipartite (CIB) e Tripartite (CIT), e expressa por meio de normas administrativas, geralmente decorrentes de pactuações realizadas entre as instâncias do SUS (16). A organização se faz em redes e de forma regionalizada, para que cada região de saúde tenha a capacidade de integrar serviços de responsabilidade da União, Estado, Municípios e Distrito Federal (17).

A partir da análise realizada, verificou-se que, em ambos os anos, mais de $40 \%$ dos processos que tiveram bloqueio de valores foram demandados por advogado particular, seguindo o perfil geral das ações judiciais de assistência à saúde no Estado. O predomínio de ações conduzidas por escritórios de advocacia poderia sugerir que, provavelmente, os requerentes possuem condições financeiras mais favoráveis para arcar com um advogado particular, indicando que a procura pelo Poder Judiciário, como via de acesso às tecnologias em saúde, está vinculada ao maior acesso à informação, assim como condições socioeconômicas mais favoráveis (18). Entretanto, Gomes e Amador (19), em 2015, advertiram que a advocacia privada não é um bom indicador de condição de classe, pois muitas vezes os custos processuais podem ser financiados por laboratórios farmacêuticos e distribuidoras de medicamentos, com graves conflitos de interesse.

Em Santa Catarina, a Defensoria Pública (DP-SC) foi criada apenas em 2012, por meio da Emenda Constitucional Estadual n 62/2012, que adequou o art. 104 da Constituição 
do Estado de Santa Catarina ao art. 134 da Constituição Federal (20). Conforme a Lei Complementar ํㅗ 575, de 2 de agosto de 2012 (21), a qual dispõe sobre a organização e funcionamento da DP-SC, trata-se de uma instituição essencial à função jurisdicional do Estado, cuja incumbência é oferecer orientação jurídica e defesa gratuitas, em todos os graus, aos necessitados, assim considerados os que comprovarem insuficiência de recursos. De acordo com a Lei, necessitado é todo aquele cuja situação econômica não lhe permita pagar às custas do processo e os honorários de advogado, sem prejuízo do sustento próprio ou da família. A renda familiar não pode ser superior a três salários-mínimos, existindo exceção para quatro salários-mínimos na situação de famílias com mais de cinco membros e também quando a família não possui bens superiores a 150 salários-mínimos. A DP-SC é a terceira com menor número de defensores no Brasil e não possui uma defensoria especializada em saúde, como acontece em Minas Gerais (22), ou seja, os defensores atuam em diferentes áreas com acúmulo de demandas. Tal quadro, somado aos critérios socioeconômicos mencionados, poderia justificar o fato de não ser a representação judicial predominante nas ações judiciais no presente estudo.

Conforme a Tabela 1, verificou-se que, em ambos os períodos, predominou o bloqueio de fato, quando o autor da ação não recebe a tecnologia deferida, informa nos autos e o juiz determina o bloqueio da conta pública e o respectivo depósito em conta do autor, para que o mesmo efetue a compra da tecnologia deferida. O bloqueio de conta pública também pode se dar mediante ao ressarcimento do autor pela compra da tecnologia, quando o mesmo, ao não receber, realiza a compra e, posteriormente, apresenta a nota fiscal nos autos, solicitando o ressarcimento (reembolso) do valor desprendido para a compra da tecnologia. Verificou-se ainda que, para alguns autores, foram determinadas as duas formas: o ressarcimento, referente a uma compra anterior; e o bloqueio, para garantir o tratamento futuro. Em ambos os períodos analisados, em mais de $90 \%$ das decisões foi determinado o bloqueio de verbas somente contra o Estado de Santa Catarina. Em 2015, esse resultado deve-se ao fato de que, na maior parte dos processos analisados, o réu era somente o Estado, no entanto, isso não aconteceu em 2016, como já apresentado previamente. Devese atentar ao fato de que, mesmo os três entes sendo réus, ao emitir o despacho, o juiz determina, em algumas situações, qual ente deve ser responsável pelo cumprimento. Em geral, o Estado acaba sendo compelido ao fornecimento, com posterior ressarcimento 
solidário da União e/ou Município, o que muitas vezes não acontece.

Em dezembro de 2015, verificou-se que não houve predomínio de solicitação de bloqueio em Comarca/Subseção Judiciária específica. O contrário foi observado na análise do ano seguinte, em que a maior parte das solicitações de bloqueio de verbas públicas teve como principal representante a região de Criciúma, no sul do estado, incluindo processos da Justiça Estadual e Federal. De acordo com dados do TJSC (23), em 2016, nas 114 comarcas do Estado foram distribuídos 8.387 processos, cujos assuntos estavam relacionados ao fornecimento de medicamentos, tratamento médico-hospitalar e unidade de terapia intensiva. Verifica-se o predomínio de ações da região sul do Estado, como os municípios de Tubarão, Criciúma e Imbituba, indo ao encontro dos dados desse estudo. Esse predomínio específico por comarca pode estar associado ao maior conhecimento e melhor compreensão dessa via de acesso pelos prescritores e pelos representantes jurídicos dessas localidades. No entanto, se faz necessária a realização de estudos mais específicos para analisar tal hipótese.

O impacto no crescimento dos bloqueios nas contas públicas para o cumprimento das ações judiciais por medicamentos ganhou força com a PSV $n^{\circ} 4$, feita pela DPU e legitimada pelo parecer da PGR, diante da falta de definição quanto a Súmula, por parte do STF, e a jurisprudência construída em recurso do STJ, julgado no final de $2013(5,6,7,8)$. O cenário não deve se alterar no ano de 2019, pois no último dia 17 de outubro de 2019, o julgamento do RE n 566471 foi excluído do calendário pelo presidente do STF (6). Diante da incerteza que permanece sobre o dever do Estado de fornecer medicamentos de alto custo aos portadores de doença grave, que não possuem condições financeiras para adquiri-los, segue uma inconsistência em relação à universalidade do direito à saúde, definida na Constituição Federal de 1988 (15). A interpretação judicial de que os cidadãos com piores condições econômicas devem receber os medicamentos de alto custo, fere o princípio doutrinário do SUS de que todos devem receber a assistência integral em saúde independente de suas posses (24). Tal entendimento se configuraria na perspectiva de uma parte da seguridade social que seria a assistência social.

Além de ferir os princípios do SUS, a obrigatoriedade do custeio poderia gerar danos ainda maiores aos orçamentos públicos, ampliando o subfinanciamento do sistema, ao cumprir demandas individuais que se pautam em altos valores dos medicamentos, sem 
pensar na dimensão coletiva da saúde pública (25). Como expresso pelo Ministro Luís Roberto Barroso, em seu voto sobre o referido julgamento:

"Não há sistema de saúde que possa resistir a um modelo em que todos os remédios, independentemente de seu custo e impacto financeiros devam ser oferecidos pelo Estado a todas as pessoas. É preciso, tanto quanto possível, reduzir e racionalizar a judicialização da saúde, bem como prestigiar as decisões dos órgãos técnicos, conferindo caráter excepcional à dispensação de medicamento não incluído na política pública (6)."

Os medicamentos denominados popularmente de alto custo, em sua maioria, compõem o denominado Componente Especializado da Assistência Farmacêutica, que é financiado unicamente pela União ou em divisão com os Estados da federação. Existe uma política pública definida pelo Ministério da Saúde, que contempla vários medicamentos, dividindo-os por competências entre os entes federados, conforme grupos 1A, 1B e 2 (26). Quando o cidadão aciona a justiça para obter um medicamento, que talvez seja da competência da União, a demanda chega ao município, que pode ser obrigado a fornecer um medicamento com valor incompatível com o próprio orçamento desse ente federado, visto que a responsabilidade solidária, na perspectiva do direito à saúde, se mantém (27).

Em relação ao crescimento nos bloqueios judiciais em Santa Catarina, observou-se aumento no tempo médio dos sequestros nas contas estaduais. O tempo médio de bloqueio, em dezembro de 2015, considerando o determinado na decisão judicial, foi de $1,69( \pm 0,81)$ meses e mediana de um mês. Já em dezembro de 2016, a média foi de $3,96( \pm 3,50)$ meses, com mediana de três meses. Quando o bloqueio de valores é determinado por longos períodos, o juiz expede o alvará para a liberação do valor bloqueado, aproximadamente a cada três meses, e o autor deve comprovar a compra da tecnologia, apresentando a nota fiscal nos autos nesse período. No entanto, isso pode contribuir para que o autor receba em duplicidade, pois, além de ter recebido o valor para adquirir a tecnologia, o sistema que gerencia as ações judiciais no Estado não administra os valores bloqueados e, com o reabastecimento, a tecnologia acaba sendo enviada para o município do autor, evidenciando uma falta de controle e gerenciamento desse tipo de ação.

Observa-se que o Judiciário tem, cada vez mais, adotado medidas para garantir o cumprimento desse tipo de decisão. Em maio de 2018, o juiz da 21ํ Vara Federal Cível do Distrito Federal, Rolando Valcir Spanholo, deferiu uma liminar determinando que a União 
reserve verbas para o bloqueio de valores em suas contas, via sistema Bacen Jud, e assim, assegure o cumprimento das decisões judiciais em saúde (28). Uma situação que desorganiza ainda mais o planejamento do SUS, ferindo a Lei $n^{\circ} 8.142 / 1990$, que trata do controle social, e a Lei Complementar $n^{\circ} 141 / 2012$, que regula o financiamento do SUS nos três entes federados

Conforme demonstrado na Tabela 2, foram observadas 47 tecnologias referentes ao mês de dezembro de 2015 e 253 tecnologias relativas a dezembro de 2016. Em ambos os períodos analisados, predominaram os medicamentos, sendo que o restante variou entre insumo e nutrição. Devido a esse elevado percentual, algumas variáveis analisadas neste estudo referem-se somente a medicamentos.

Tabela 2. Variáveis relacionadas às tecnologias solicitadas nos processos com bloqueio de verbas públicas, nos meses de dezembro de 2015 e dezembro de 2016

\begin{tabular}{l|ll}
\hline \multirow{2}{*}{ Variável } & \multicolumn{2}{|c}{ Mês/Ano } \\
\cline { 2 - 3 } & Dezembro 2015 & Dezembro 2016 \\
\cline { 2 - 3 } $\begin{array}{l}\text { Origem receituário } \\
\text { SUS }\end{array}$ & $36,17 \%(17)$ & $59,29 \%(150)$ \\
Não-SUS & $63,83 \%(30)$ & $40,71 \%(103)$ \\
\hline Tipo de tecnologia & & \\
Insumo & $8,51 \%(4)$ & $2,37 \%(6)$ \\
Medicamento & $80,85 \%(38)$ & $93,68 \%(237)$ \\
Nutrição & $10,64 \%(5)$ & $3,95 \%(10)$ \\
\hline Prescrição & & \\
Por DCB & $29,79 \%(14)$ & $24,90 \%(63)$ \\
Por nome comercial & $63,83 \%(30)$ & $73,52 \%(186)$ \\
Não se aplica & $6,38 \%(3)$ & $1,58 \%(4)$ \\
\hline Lista oficial & & \\
Não & $70,21 \%(33)$ & $90,12 \%(228)$ \\
Sim, Rename & $8,51 \%(4)$ & $7,51 \%(19)$ \\
Não se aplica & $21,28 \%(10)$ & $2,37 \%(6)$ \\
\hline Registro na Anvisa & & \\
Não & $0,00 \%(0)$ & $0,79 \%(2)$ \\
Sim & $100 \%(47)$ & $99,21 \%(251)$ \\
\hline Indicação judicializada é aprovada em bula & $2,13 \%(1)$ & $1,19 \%(3)$ \\
Não & &
\end{tabular}




\begin{tabular}{l|ll}
\hline \multirow{2}{*}{ Variável } & \multicolumn{2}{|c}{ Mês/Ano } \\
\cline { 2 - 3 } & Dezembro 2015 & Dezembro 2016 \\
\cline { 2 - 3 } & $\%(\mathrm{n}=47)$ & $\%(\mathrm{n}=253)$ \\
\hline Sim & $80,85 \%(38)$ & $91,70 \%(232)$ \\
Não se aplica* & $17,02 \%(8)$ & $7,11 \%(18)$ \\
\hline Juiz permite troca por genérico & & \\
Sim & $6,38 \%(3)$ & $21,34 \%(54)$ \\
Não & $0,00 \%(0)$ & $0,79 \%(2)$ \\
Não mencionado & $93,62 \%(44)$ & $77,87 \%(197)$ \\
\hline Contracautela & \multicolumn{2}{|}{} \\
Sim & $65,95 \%(31)$ & $81,42 \%(206)$ \\
Não & $34,05 \%(16)$ & $18,58 \%(47)$ \\
\hline
\end{tabular}

Fonte: elaboração própria.

Legenda: Anvisa (Agência Nacional de Vigilância Sanitária); DCB (Denominação Comum Brasileira); Rename (Relação Nacional de Medicamentos Essenciais); SUS (Sistema Único de Saúde).

* Os insumos e nutrições não possuem bula.

Em dezembro de 2015, a maioria das prescrições analisadas (medicamentos, insumos e nutrições) era proveniente da rede particular, já no ano seguinte, mais da metade eram oriundas da rede pública. O maior volume de prescrições provenientes da rede pública, em dezembro de 2016, chama atenção para o fato de muitos autores utilizarem a rede pública de saúde para obter uma prescrição, o que muitas vezes, determina uma maior confiança do Judiciário para deferir o pedido judicial. Esses autores não buscam seu atendimento integralizado na rede pública, utilizam apenas com intuito de acessar tecnologias não cobertas. Tal fato pode acontecer também devido ao desconhecimento dos prescritores em relação às listas padronizadas e aos critérios de inclusão e exclusão dos protocolos clínicos e diretrizes terapêuticas do Ministério da Saúde, além da influência perniciosa da indústria farmacêutica, conforme relatado por Campos Neto $(29,30)$.

Em relação à prescrição de medicamentos, mais de $60 \%$ dos receituários analisados foram prescritos pelo nome comercial. A Lei ํㅜ 9.787/1999, em seu art. $3^{\circ}$, dispõe que as prescrições médicas e odontológicas de medicamentos, no âmbito do SUS, devem adotar obrigatoriamente a denominação comum brasileira (DCB) ou, na sua falta, a denominação comum internacional (DCl) (31). O Decreto oㅜ 241/2015 do governo de Santa Catarina, baseado na referida Lei, também reforça que os médicos e odontólogos servidores estaduais devem adotar obrigatoriamente a $\mathrm{DCB}$ ou, na sua falta, a $\mathrm{DCl}$, constando o nome do princípio 
ativo e, quando pertinente, o nome de referência da substância (32).

Campos Neto et al (29) analisaram a associação entre médicos e escritórios de advocacia nas solicitações dos medicamentos. Segundo eles, médicos do setor privado predominaram entre os responsáveis pelas prescrições que levaram à judicialização dos medicamentos em Minas Gerais, local onde o estudo foi conduzido. Os resultados sugeriram a relação entre um escritório de advocacia e um médico específicos, o que poderia indicar uma parceria entre esses profissionais e o laboratório fabricante do medicamento prescrito, já que o médico foi responsável por cerca de 44\% das prescrições do medicamento, em 117 ações judiciais analisadas. Pode-se deduzir que as ações judiciais não seguem um padrão condizente com a legislação sanitária no que se refere à padronização das prescrições de medicamentos, estando possivelmente sob a influência da indústria farmacêutica (29).

Mais de $70 \%$ dos medicamentos constantes nos processos que tiveram bloqueio de valores, em ambos os períodos analisados, não constavam em nenhuma lista de padronização de medicamentos, como a Relação Nacional de Medicamentos Essenciais (Rename). Tal fato pode estar relacionado à refratariedade dos pacientes aos tratamentos oferecidos pelo SUS, desatualização ou ausência de protocolos clínicos para as indicações clínicas solicitadas e captura dos médicos pela indústria farmacêutica (29, 30).

Verifica-se que o perfil de medicamentos solicitados judicialmente não corresponde às necessidades coletivas na forma com que são contempladas pelas políticas públicas de saúde, pois a maioria dos medicamentos não pertence a uma lista oficial, ou seja, fica claro que o predomínio de solicitações na via judicial é fruto de necessidades individuais, visto que a maioria das ações é requerida individualmente, conforme já demonstrado. O fato de se recorrer à judicialização também evidencia as dificuldades no acesso às políticas públicas, fazendo com que haja um maior debate na sociedade em relação aos tratamentos oferecidos. Quando o Estado formula as políticas públicas de saúde, pretende garantir na prática o direito à saúde universal e integral preconizado pela Constituição, para que haja redução das iniquidades. Assim, o Estado prioriza ações e serviços que serão fornecidos, conforme a disponibilidade de recursos e com base em evidências de eficácia, segurança e custo efetividade. Por outro lado, a judicialização pode, de certa forma, interferir nas políticas públicas de saúde, ao pressionar ou induzir a avaliação de novas tecnologias, garantindo incorporações de medicamentos baseadas no alto índice de solicitação pela via judicial, e 
induzindo a atualização dos programas e protocolos que devem acompanhar o desenvolvimento de novas práticas terapêuticas. Conforme revisão sistemática, publicada por Gomes e Amador (19), muitos dos medicamentos constantes nas ações judiciais se encontram padronizados pelo Ministério da Saúde, já que grande parte dos dados analisados se refere a processos que tramitaram entre 2000 e 2006 . Os autores do estudo relatam que não foram encontrados dados mais recentes publicados e que o avanço das políticas públicas pode estar relacionado às demandas criadas judicialmente, contribuindo para a incorporação de produtos nas listas oficiais da política de assistência farmacêutica atual.

Em relação ao registro na Anvisa, em ambos os períodos, todos os medicamentos judicializados apresentavam registro vigente na agência, no momento do estudo (20152016). Há de se atentar para o fato de que a solicitação de um produto sem registro na Anvisa pode implicar em um maior custo para a sua aquisição, quando comparado ao fornecimento de produtos disponíveis em território nacional. Ainda há de se considerar a morosidade do trâmite relacionado ao processo de importação que, para compras públicas, leva em torno de três a seis meses. Além disso, a não concessão de registro pela agência reguladora está associada à qualidade, segurança e eficácia da tecnologia, podendo o uso dos medicamentos pelo paciente gerar risco a sua saúde.

Verificou-se que, entre os 300 medicamentos analisados nos dois períodos, mais de 80\% possuíam indicação clínica prevista em bula, na vigência do estudo. Essa variável não foi analisada para insumos, nutrições e medicamentos, cujo registro na Anvisa não foi localizado. Apenas um medicamento no período de 2015 e três medicamentos no período de 2016 configuraram como uso off-label, ou seja, sem indicação prevista em bula.

$\mathrm{Na}$ maioria dos processos analisados, ao emitir a decisão, o juiz não mencionou a possibilidade de troca por medicamento genérico e/ou similar. Na análise referente a 2016, pouco mais de $20 \%$ dos juízes possibilitaram ao (s) réu (s) o fornecimento do medicamento genérico ou similar com a mesma eficácia comprovada. Já em relação à contracautela, notase, pelos resultados apresentados, que a maioria dos juízes a estabeleceram. A contracautela é uma condição determinada pelo juiz, ao emitir uma decisão favorável ao autor, quando se faz necessária a inclusão, nos autos, de documentação comprobatória sobre a necessidade de manutenção do tratamento. A periodicidade é definida pelo próprio 
juiz, considerando a situação do autor. Em dezembro de 2015 e dezembro de 2016, a maioria das contracautelas determinadas pelo juiz foi de três meses, seguido pelo período de seis meses.

Ao analisar os processos que tiveram bloqueio de valores em dezembro de 2015, levando-se em consideração as variáveis dos autores, verificou-se que a faixa etária predominante foi de 20-59 anos de idade, configurando uma população adulta, diferentemente do verificado em dezembro de 2016, no qual houve o predomínio de idosos, com 60 anos ou mais.

Em relação às CID-10 descritas pelos médicos, houve o predomínio das CIDs referentes a neoplasias, doenças endócrinas, nutricionais ou metabólicas e transtornos mentais e comportamentais, nos processos referentes a dezembro de 2015. Já no período de 2016, um maior número de solicitações de tratamento para doenças endócrinas, nutricionais ou metabólicas foi verificado.

No tocante ao município de residência dos autores, em dezembro de 2015, não houve predomínio considerável de um município, sendo estes bem distribuídos. No mês de dezembro de 2016, foi possível observar um predomínio de autores oriundos do município de Criciúma, assim como da região sul do Estado, abrangendo os municípios de Urussanga, Nova Veneza, Içara, Cocal do Sul e Araranguá. No entanto, mais estudos devem ser realizados a fim de justificar o predomínio de ações provenientes desta região, assim como deve ser considerado o índice populacional desses municípios, o qual pode influenciar na frequência das ações judiciais.

\section{Gastos associados aos bloqueios de verbas públicas}

Os gastos dos processos judiciais com bloqueios nas contas públicas, determinados em dezembro de 2015 e dezembro de 2016, podem ser visualizados no Gráfico 1. Percebese que, em dezembro de 2016 , houve um aumento de $858,82 \%$ nos gastos, em relação a dezembro de 2015. Esse crescimento pode ser justificado pelo aumento do número de ações judiciais e também pelo aumento do descumprimento no atendimento das decisões por parte dos réus. 
Gráfico 1. Gasto total com processos que tiveram bloqueio de verbas públicas ( $R \$$ ), dezembro de 2015 e dezembro de 2016

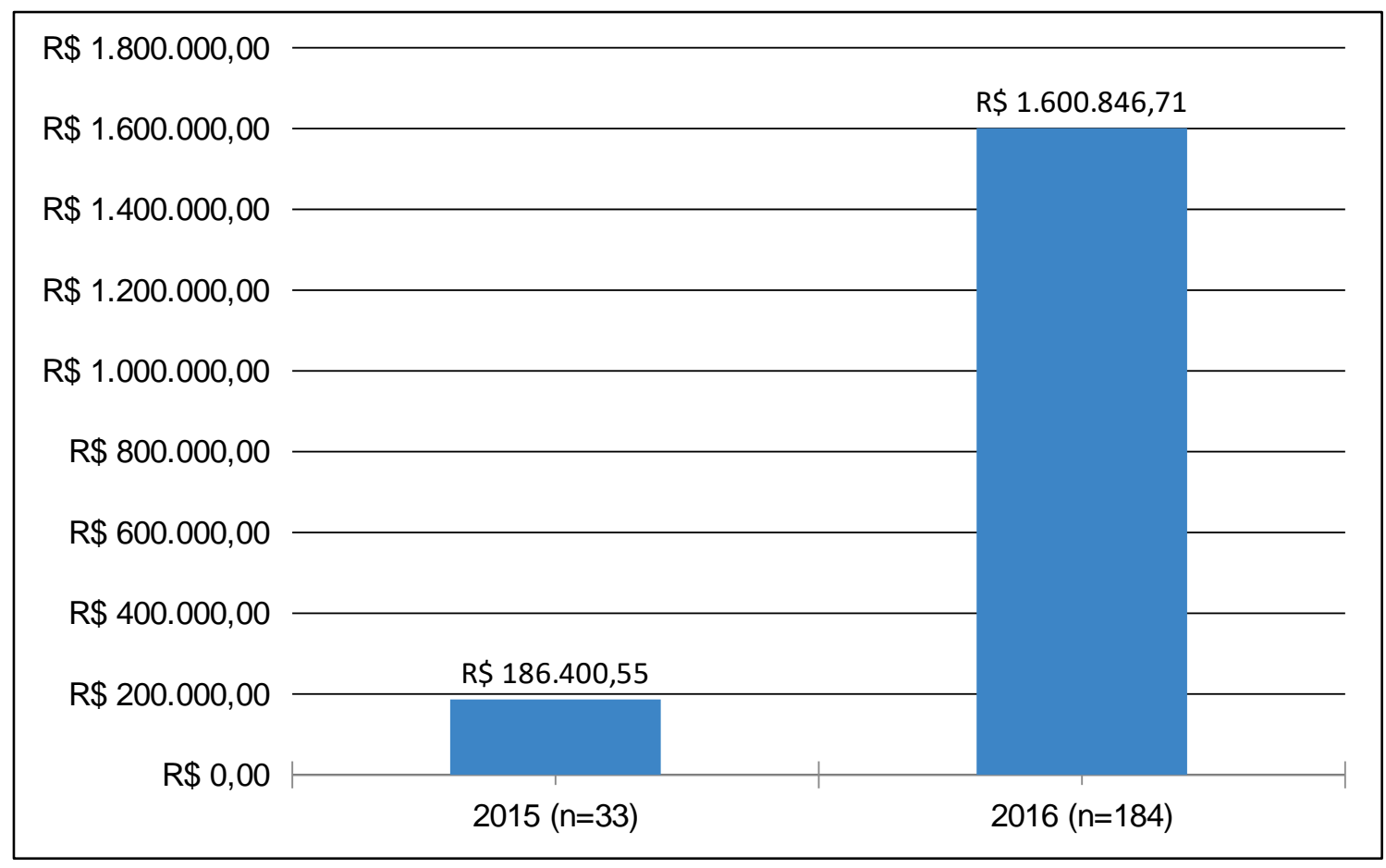

Fonte: elaboração própria.

Os valores apresentados referem-se ao bloqueio determinado pelo juiz na decisão, considerando o total de processos da análise por período, não sendo levado em consideração o período determinado do bloqueio ou ressarcimento de valores, ou seja, tratase do somatório dos valores bloqueados determinados nas decisões.

Em dezembro de 2015, o gasto mensal com processos que tiveram bloqueio de verbas públicas foi de $R \$ 135.549,39$, no entanto, se o Estado tivesse cumprido as decisões e realizado a compra das tecnologias por meio administrativo, o gasto mensal teria sido de

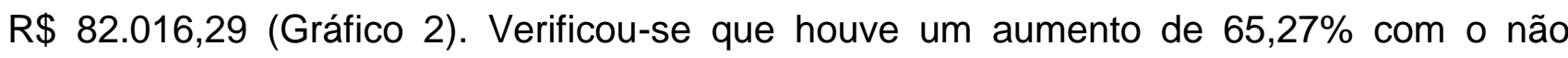
cumprimento dessas decisões e a consequente determinação de bloqueio de valores das contas do Estado. 
Gráfico 2. Comparação entre o gasto mensal com processos que tiveram bloqueio de verbas públicas $(R \$)$ e o gasto mensal com a compra das tecnologias pleiteadas pela Secretaria de Estado da Saúde, dezembro de 2015 e dezembro de 2016

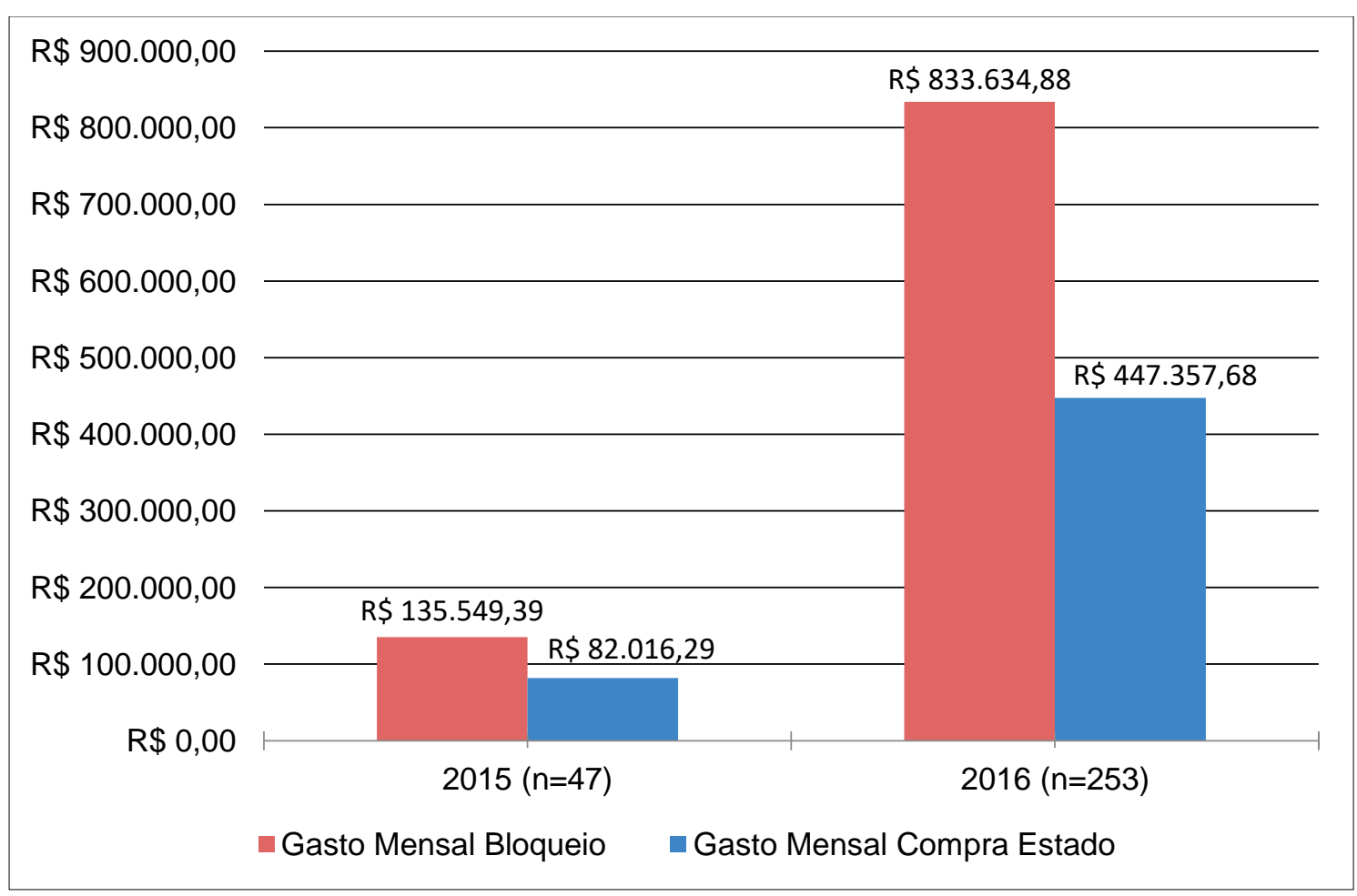

Fonte: elaboração própria.

No mês de dezembro de 2016, o gasto mensal com processos que tiveram bloqueio de verbas públicas foi de $\mathrm{R} \$ 833.634,88$, e, caso o Estado realizasse a compra para o atendimento o gasto, seria de $\mathrm{R} \$ 447.357,68$, correspondendo a um aumento de $53,67 \%$ nos gastos.

Também foi observado que, em 2015, entre as 47 tecnologias analisadas, apenas quatro delas apresentavam valor superior, caso o Estado as tivesse adquirido, isto é, o valor da compra da tecnologia com o bloqueio de valor seria menos oneroso ao Estado. Da mesma forma, foram verificadas apenas oito tecnologias em 2016.

É importante ressaltar que o Estado deve se valer do processo licitatório para aquisição de terceiros, com o objetivo de escolher a proposta mais vantajosa para a Administração Pública, levando em conta a economia e o previsto na Lei oㅡ 8.666/1993. Em relação aos preços dos medicamentos, a Anvisa exerce a função de secretaria executiva da 
Câmara de Regulação do Mercado de Medicamentos (CMED), órgão interministerial responsável por regular o mercado e estabelecer critérios para a definição e o ajuste de preços. A CMED, por meio da Resolução $\mathrm{n}^{\circ}$ 2, de 5 de março de 2004, criou o preço de fábrica ou fabricante (PF) e o coeficiente de adequação de preços (CAP). O PF é o preço praticado pelas empresas produtoras ou importadoras do produto e pelas empresas distribuidoras. É o preço máximo permitido para venda a farmácias, drogarias e para entes da Administração Pública. Já o CAP é um desconto mínimo obrigatório, incidente sobre o PF de alguns medicamentos, nas compras realizadas pelos entes da Administração Pública direta e indireta da União, dos Estados, do Distrito Federal e dos Municípios (33). A aplicação do CAP sobre o PF resulta no PMVG, que é o preço máximo de venda ao governo, sendo, pois, o maior preço permitido para venda do medicamento a entes da Administração Pública (34).

Por meio da Orientação Interpretativa n 02/2006, a CMED determina que: "Nos fornecimentos para órgãos públicos através de licitações ou não, o Distribuidor é obrigado a vender os produtos, tendo como referencial máximo o preço fabricante" (35). Ainda, a Resolução $n^{\circ}$ 4/2006 regulamenta, em seu art. 1으, que as distribuidoras, empresas produtoras de medicamentos, representantes, postos de medicamentos, unidades volantes, e farmácias e drogarias devem aplicar o CAP ao preço dos produtos definidos no art. $2^{\circ}$ dessa Resolução, sempre que realizarem vendas a entes da Administração Pública (36).

Quando o procurador da parte informa nos autos o descumprimento da decisão e solicita o bloqueio de verbas públicas, o juiz, na maioria dos casos, solicita a apresentação de três orçamentos de farmácias de rede privada e determina o bloqueio com base no menor preço. No entanto, ao adquirir um medicamento em uma farmácia de rede privada, o valor do medicamento é baseado no preço máximo ao consumidor (PMC), que é o preço máximo permitido para venda ao consumidor e inclui os impostos incidentes por Estado, não sendo aplicado o CAP.

Dessa forma, verifica-se que o Estado, ao deixar de atender as determinações judiciais e estar sujeito à determinação do bloqueio de valores das contas públicas, para que o autor possa adquirir seu medicamento por conta própria, acaba onerando ainda mais as contas públicas.

De acordo com uma reportagem vinculada no Diário Catarinense, jornal de circulação 
estadual, em setembro de 2017, os gastos com bloqueio de valores para atendimento de ações judiciais em saúde no Estado de Santa Catarina passaram de $R \$ 7,1$ mil em 2014, para $\mathrm{R} \$ 39,8$ milhões em 2016 (4).

Considerando que, em 2016, foram gastos quase $R \$ 117$ milhões no cumprimento de decisões judiciais em saúde (37), somados aos quase $R \$ 40$ milhões em bloqueio de verbas públicas, estima-se que tenham sido gastos $R \$ 157$ milhões para o atendimento de ações em assistência à saúde. Salienta-se que, se houvesse o atendimento por parte do Estado e a compra fosse realizada de forma administrativa, com a aplicação dos descontos que a Administração Pública tem direito, o valor para cumprimento das decisões judiciais poderia ser reduzido.

\section{Considerações finais}

A judicialização da saúde tornou-se uma nova forma de acesso a assistência à saúde e tem sido motivo de preocupações e debates entre gestores do SUS, visto que a mesma tende a inviabilizar e comprometer ainda mais o planejamento e a organização das políticas públicas vigentes. O maior debate em relação a esse fenômeno é a questão orçamentária, uma vez que impacta na gestão pública, já que tais gastos não estão previstos no orçamento; afeta diretamente as condições de atuação política; onera os cofres públicos; e compromete o atendimento da população que não é privilegiada com esse tipo de atendimento.

Somado a isso, a Proposta de Súmula Vinculante $n^{\circ} 4$, cujo julgamento ainda não tem data definida, deve impactar consideravelmente nas decisões referentes à bloqueio de valores, visto que, de acordo com a referida Proposta, será julgada a legitimidade de realizar o bloqueio para garantir o fornecimento de medicamentos e tratamento médico, impactando no crescimento dos bloqueios devido ao descumprimento dos réus.

Este estudo permitiu verificar o perfil de ações judiciais em assistência à saúde com bloqueio de verbas públicas devido ao descumprimento dessas decisões. A partir do perfil levantado, verificou-se que o bem individual e os escritórios de advocacia particulares prevalecem, sugerindo que a judicialização da saúde visa ao direito individual. Notou-se também que as tecnologias solicitadas possuem registro na Anvisa, mas não pertencem a programas governamentais, indicando se tratar de tecnologias cuja incorporação ainda não foi avaliada pelo órgão competente, a Conitec, ou de tecnologias que não apresentaram 
evidências de benefícios clínicos superiores às já disponíveis, sendo a via judicial utilizada como a única forma de garantir o tratamento e também de pressionar o processo de incorporação.

Quanto aos gastos, verificou-se que há uma diferença considerável entre gastos com o atendimento de uma demanda judicial de forma administrativa - cuja aquisição das tecnologias se dá por licitação/compra direta - e os gastos com a determinação do bloqueio, no qual a tecnologia é adquirida pelo próprio autor, não havendo aplicação dos descontos que o ente público tem direito.

O bloqueio de valores torna a judicialização ainda mais onerosa ao erário e é fato que, independentemente do bloqueio, o Poder Público perde, pois a judicialização interfere excessivamente no planejamento, organização e regulação do SUS, descontrói políticas públicas vigentes, mesmo as que apresentam indicadores de saúde positivos, e desconsidera as políticas de incorporação de tecnologias. Torna-se claro que a judicialização da saúde é um novo ramo do mercado, legitimado pelo Poder Judiciário, alimentado pelo Poder Executivo e ainda negligenciado pelo Legislativo, sendo necessário mergulhar na análise dos três poderes para saber qual desses fortalece o fenômeno.

Além disso, o bloqueio é uma estratégia que vem sendo disseminada e que, no decorrer no tempo, com a crise econômica vigente, tende a se tornar uma prática cada vez mais usual para garantia do cumprimento das decisões e, por onerar significativamente, agrava ainda mais a crise econômica da administração pública.

\section{Referências}

1. D'Espíndula TCDAS. Judicialização da medicina no acesso a medicamentos: reflexões bioéticas. Rev. Bioé. 2013;21(3):438-47

2. Ramos RDS, Gomes AMT, Oliveira DC, Marques SC, Spindola T, Nogueira VPF. O acesso às ações e serviços do Sistema Único de Saúde na perspectiva da judicialização. Rev. Latino-Am. Enfermagem. 2016;24; e2797

3. Gomes FFC, Cherchiglia ML, Machado CD, Santos VC, Acurcio FA, Andrade EIG. Acesso aos procedimentos de média e alta complexidade no Sistema Único de Saúde: uma questão de judicialização. Cad. Saúde Pública. 2014 jan;30(1):31-43 
4. Diário Catarinense (BR). Pacientes recorrem à justiça para sobreviver [Internet]. 2017 [citado em 8 jul. 2019]. Disponível em: http://clicrbs.com.br/sites/swf/dc_saude_em_crise /judicializacao.html.

5. Cunha ALCV. Sistema Bacen Jud de bloqueio judicial: princípios norteadores e controvérsias existentes quanto sua aplicação [Monografia]. Brasília (BR): Centro Universitário de Brasília; 2013.

6. Supremo Tribunal Federal (BR). Recurso Extraordinário o 566471 [Internet]. Brasília: STF; 2019 Out [citado em 10 out. 2019]. Disponível em: http://www.stf.jus.br/portal/pauta /verTema.asp?id=97270\#

7. Supremo Tribunal Federal (BR). Súmula Vinculante no 4 [Internet]. Brasília: STF; 2019 Out [citado em 10 out. 2019]. Disponível em: http://www.stf.jus.br/portal/jurisprudencia/ menuSumario. asp?sumula $=1195$

8. Supremo Tribunal Federal (BR). Recurso Especial oㅜ 1.069.810 [Internet]. Brasília: STF; 2013 Out [citado em 10 out. 2019]. Disponível em: http://www.fehosp.com.br/files/arquivos/ Resp-1-069-810-RS.pdf

9. Classificação Estatística Internacional de Doenças e Problemas Relacionados à Saúde CID-10. [citado em 14 abr. 2019]. Disponível em: http:/www.datasus.gov.br/cid10/N2008/cid10.htm.

10. Ronsein JG. Análise do perfil das solicitações de medicamentos por demanda judicial no Estado de Santa Catarina no período de 2005 a 2008 [Dissertação]. Florianópolis (SC): Universidade Federal de Santa Catarina. 2010.

11. Travassos V, Ferreira RC, Vargas AMD, Moura RNVDM, Conceição EMDA, Marques DDF, et. al. Judicialização da saúde: um estudo de caso de três tribunais brasileiros. Ciência \& Saúde Coletiva. 2013 nov;18(11):3419-29.

12. Coelho TL, Ferré F, Campos OH Nt, Acurcio FDA, Cherchiglia ML, Andrade EIG. Variáveis jurídicas e de saúde no deferimento de liminares por medicamentos em Minas Gerais. Rev.Saúde Pública. 2014 out;48(5):808-16.

13. Schulze CJ. Cabe mandado de segurança para pedir medicamento? [Internet]. Florianópolis (SC): Empório do Direito; 2016 Jun [citado em 20 mai. 2019]. Disponível em: http://emporiododireito.com.br/leitura/cabe-mandado-de-seguranca-para-pedirmedicamento-por-clenio-jair-schulze.

14. Supremo Tribunal Federal (BR). Recurso extraordinário oㅡ 855.178, de 2015. 2015 Mar [citado em 13 jul. 2019]. Disponível em: http://jusbrasil.com.br.

15. Supremo Tribunal Federal (BR). Constituição da República Federativa do Brasil [Internet]. Brasília: STF; 2019 Out [citado em 10 out. 2019]. Disponível em: http://www.stf.jus.br/portal/constituicao/artigoBd.asp?item=357 
16. Pepe VLE, et al. Caracterização de demandas judiciais de fornecimento de medicamentos "essenciais" no Estado do Rio de Janeiro, Brasil. Cad. Saúde Pública. 2010 mar; 26(3): 461-471.

17. Santos L. Decisão parcial do STF quanto ao fornecimento de medicamento de alto custo sem registro no país. Direito do Estado. 2016 Num 272 [Internet]. [citado em 10 out. 2019]. Disponível em: http://www.direitodoestado.com.br/colunistas/lenir-santos/decisao-parcialdo-stf-quanto-ao-fornecimento-de-medicamento-de-alto-custo-sem-registro-no-pais

18. Boing A, Bloemer N, Roesler C, Fernandes S. A judicialização do acesso aos medicamentos em Santa Catarina: um desafio para a gestão do sistema de saúde. RDisan [Internet]. 12jun.2013 [citado em 20 jul. 2019];14(1):82-7. Disponível em: http://www.revistas.usp.br/rdisan/article/view/56625

19. Gomes VS, Amador TA. Estudos publicados em periódicos indexados sobre decisões judiciais para acesso a medicamentos no Brasil: uma revisão sistemática. Cad. Saúde Pública. 2015 mar;31(3):451-62.

20. Santa Catarina. Constituição do Estado de Santa Catarina. [citado em 27 set. 2019]. Disponível em: http://leisestaduais.com.br/lei/constituicao-estadual-sc

21. Santa Catarina. Lei Complementar $n^{\circ}$ 575, de 02 de agosto de 2012. Cria a Defensoria Pública do Estado de Santa Catarina, dispõe sobre sua organização e funcionamento e estabelece outras providências. [citado em 27 set. 2019]. Disponível em: http://leis.alesc.sc.gov.br/html/2012/575_2012_Lei_complementar.html

22. Defensoria Pública de Minas Gerais. [citado em 27 set. 2019]. Disponível em: https://www.defensoria.mg.def.br/servicos/carteira-de-servicos/saude/

23. Corregedoria Geral da Justiça. Consulta processos contra saúde [Internet]. Mensagem para: Sabrina Vilvert. 2017 Set 22 [citado em 27 mai. 2019]. BRASIL.

24. BRASIL. Lei no 8.080 de 19 de setembro de 1990 - Dispõe sobre as condições para a promoção, proteção e recuperação da saúde, a organização e o funcionamento dos serviços correspondentes e dá outras providências. Diário Oficial da União, 1990. [citado em 26 out 2019]. Disponível em: http://planalto.gov.br.

25. Santos AO, Lopes LT. Coletânea direito à saúde: dilemas do fenômeno da judicialização da saúde. Brasília (DF): CONASS, 2018. 319p.

26. Brasil. Ministério da Saúde. Portaria de Consolidação nำ 6, de 28 de setembro de 2017. Consolidação das normas sobre o financiamento e a transferência dos recursos federais para as ações e os serviços de saúde do Sistema Único de Saúde. Brasília: Biblioteca Virtual em Saúde, 2019. Out [citado em 26 out. 2019]. Disponível em: http://bvsms.saude.gov.br/bvs/saudelegis/gm/2017/prc0006_03_10_2017.html 
27. Romano RT. O limite do possível no fornecimento de medicamentos. [Internet]. Jus; 2019 Mai [citado em 26 out 2019]. Disponível em: https://jus.com.br/artigos/74158/o-limite-dopossivel-no-fornecimento-de-medicamentos.

28. Consultor Jurídico. Juiz manda União separar verba para também sofrer bloqueio via BacenJud [Internet]. São Paulo: Dublê Editorial, 2018 mai [citado em 25 mai 2019]. Disponível em: https://www.conjur.com.br/2018-mai-23/juiz-manda-uniao-separar-verbasofrer-bloqueio-via-bacenjud.

29. Campos OH Nt, Acurcio FDA, Machado MADA, Ferré F, Barbosa FLV, Cherchiglia ML, et. al. Médicos, advogados e indústria farmacêutica na judicialização da saúde em Minas Gerais, Brasil. Rev. Saúde Pública. 2012 out;46(5):784-90.

30. Campos Neto Orozimbo Henriques, Gonçalves Luiz Alberto Oliveira, Andrade Eli lola Gurgel. A judicialização da Saúde na percepção de médicos prescritores. Interface (Botucatu) [Internet]. 2018 Mar [citado em 20 jul. 2019]; 22(64): 165-176. Disponível em: http://www.scielo.br/scielo.php?script=sci_arttext\&pid=S1414-32832018000100165\&lng=en. Epub, June 05, 2017. http://dx.doi.org/10.1590/1807-57622016.0314.

31. BRASIL. Lei no 9.787, de 10 de fevereiro de 1999. Altera a Lei o 6.360, de 23 de setembro de 1976, que dispõe sobre a vigilância sanitária, estabelece o medicamento genérico, dispõe sobre a utilização de nomes genéricos em produtos farmacêuticos e dá outras providências. Brasília: Portal da Legislação, Leis Ordinárias. 1999 Fev [citado em 14 abr. 2019]. Disponível em: http://www.planalto.gov.br/ccivil_03/leis/L9787.htm.

32. Secretaria do Estado da Saúde de Santa Catarina (BR). Decreto oㅡ 241, de 30 de junho de 2015 [Internet]. 2015 Jun [citado em 15 mai. 2019]. Disponível em: http://portaldoservidor.sc.gov.br.

33. Agência Nacional de Vigilância Sanitária (BR). Resolução ํo 2, de 5 de março de 2004 [Internet]. 2004 Mar [citado em 8 mai. 2019]. Disponível em: http://portal.anvisa.gov.br.

34. Agência Nacional de Vigilância Sanitária (BR). Compras públicas, 2013 [Internet]. 2013 [citado em 8 mai. 2019]. Disponível em: http://portal.anvisa.gov.br.

35. Agência Nacional de Vigilância Sanitária (BR). Orientação Interpretativa ํㅡ 2, de 13 de novembro de 2006 [Internet]. 2006 Nov [citado em 8 jul. 2019]. Disponível em: http://portal.avisa.gov.br.

36. Agência Nacional de Vigilância Sanitária (BR). Resolução oㅡ 4, de 18 de dezembro de 2006. Dispõe sobre o Coeficiente de Adequação de Preços - CAP, sua aplicação, e altera a Resolução no 2, de 5 de março de 2004 [Internet]. 2004 Mar [citado em 8 mai. 2019]. Disponível em: http://portal.anvisa.gov.br. 
37. Secretaria de Estado da Saúde de Santa Catarina (BR), Gerência de Planejamento da Demanda de Bens e Serviços. Valores gastos no atendimento de ações judiciais [Internet]. Mensagem para: Sabrina Vilvert. 2019 jul [citado em 20 jul. 2019].

Como citar este artigo:

Vilvert SH, Buendgens FB, Campos Neto OH, Oliveira Júnior, HA. Perfil das ações judiciais em assistência à saúde com bloqueio de verbas públicas no Estado de Santa Catarina. Cadernos Ibero-Americanos de Direito Sanitário. 2019 out./dez.; 8(4): 119-144.

http://dx.doi.org/10.17566/ciads.v8i4.559 